\title{
SEGREGATION AND SOLID EVOLUTION DURING THE SOLIDIFICATION OF NIOBIUM-CONTAINING SUPERALLOYS
}

\author{
Wanhong Yang", Wei Chen", Keh-Minn Chang* \\ Sarwan Mannan ${ }^{7}$, John deBarbadillo ${ }^{\circ}$ \\ *West Virginia University, Morgantown, WV 26506-6106 \\ ${ }^{\circledR}$ Special Metals Corporation, Huntington, WV 25705
}

\begin{abstract}
A macrosegregation defect, commonly termed freckle, has limited the maximum diameter of remelted ingots of some $\mathrm{Nb}$ strengthened nickel base superalloys. Two aspects of freckle formation were studied in three commercially important superalloys 718,706 and $625: 1)$ the segregation characteristics which provide the driving force for freckle formation; 2) the solid development in the mushy zone which provides resistance to the flow inducing the defect. A Rayleigh number form freckle criterion that considers the effects of composition is derived. Freckle tendency of the alloys was evaluated using the experimental results.
\end{abstract}

\section{$\underline{\text { Introduction }}$}

The production of remelted superalloy ingots has been driven by the increasing demand from the land based gas turbine industry. However, the size of remelted ingots in production has been limited because of some technical difficulties. One of them is the risk of forming freckles. Freckle is a channel-type macrosegregation, consisting of equiaxed grains and eutectic constituents $^{[1]}$. Because of its macrosegregation nature, thermomechanical processing after remelting cannot eliminate the problem in billet products. The freckle defect is considered very harmful to the mechanical property of final products ${ }^{[2,3]}$.

Freckle has been found in directionally solidified and single crystal airfoils, steel ingots and remelted superalloy ingots ${ }^{[1-5]}$. Similar channel type macrosegregation was also observed in $\mathrm{Al}$ and $\mathrm{Ti}$ alloys ${ }^{[6]}$. The formation of the channel-type defects is believed to be related to the density gradient in the solidifying mushy zone. The density gradient is caused by the segregation of solute elements into the interdendritic liquid. This density gradient is unstable under the action of gravity. As a result of the convective hydrodynamic instability, plume flow can occur in the mushy zone. This may cause misoriented grains or eutectic constituents to form in the freckle trail ${ }^{[7-10]}$. Several studies using transparent analog system $\mathrm{NH}_{4} \mathrm{Cl}-\mathrm{H}_{2} \mathrm{O}^{[9]}$, binary tin alloys ${ }^{[8,11]}$ and computer simulation ${ }^{[12]}$ have been successful in demonstrating freckle formation in upward unidirectional solidification and in static ingot casting. The formation of freckle during remelting of $\mathrm{Nb}$-containing superalloys has also becn widcly studied and discussed ${ }^{[3-16]}$. A positive density gradient is thought to occur in the mushy zone with respect to the direction of gravity ${ }^{[13]}$. A proposed explanation of the freckle presence in this case is that the positive density gradient produces flow of interdendritic liquid that is moving downward along the sloped pool profile ${ }^{[14,15]}$. Some experimental evidence also supports the notion that the flow in the direction of secondary dendrites is easier to activate when the solidification front is tilted ${ }^{[16,17]}$

There are two basic approaches to control freckle formation in remelting. One is through the optimization of remelting practice. Improved electrode quality, intensified cooling, shallower pool and more stable melting reduce the possibility of freckles. However, in real melting the measures to intensify cooling is limited because the ingot size becomes so large that any forced cooling on ingot surface can not effectively penetrate to ingot interior. Melting system stability is limited because of the nature of remelting although significant improvements in melting control have been made.

Another approach is through alloy composition modification or alloy selection. The reason is that the density gradient inside the mushy zone is caused by solute segregation. If the segregation is so controlled that the densily gradient during solidification is minimized, the risk of freckling can be reduced.

Alloy composition not only influences the segregation behavior, but also the solid evolution during solidification. Solid in mushy zone provides resistance to any interdendritic flow inside it. As more solid is formed, the possibility of interdendritic flow is reduced. 
The scgrcgation and the solid formation behaviors of niobiumcontaining superalloys were studied with the purpose to quantitatively evaluate compositional effects. Three commercial alloys, 718, 625 and 706 were analyzed. A relative Rayleigh number accounting for the compositional effect was derived from Flemings' freckle criterion. Experimental results obtained from the three industrial alloys are incorporated into the relative Rayleigh number to quantitatively evaluate the freckle tendency of the alloys. The effects of alloying addition on density gradient and solid evolution are discussed.

\section{Experimental}

\section{Materials}

Bulk chemical composition of the materials used for the study was measured by wet chemical method and is listed in Table I. The solidification temperatures of the alloys are also listed in the Table. Niobium is added to all three alloys. Among them, alloy 718 has the highest $\mathrm{Nb}$ content and is also the most difficult to remelt. Freckle is a possibility in large diameter remelted ingots of the alloy.

\section{Microsegregation analysis}

A square mesh random sampling technique ${ }^{[18]}$ was employed to measure the solute distribution in Ni-based alloys by EDS (Electron Dispersive Spectrometry). This method is essentially the same as the systematic point count method used in quantitative metallography for the measurement of phase volume fraction ${ }^{[19]}$. A polished sample was examined under SEM to get a backscattered image. A square mesh was overlaid on the image field. The grid size of the mesh was on the order of secondary dendrite arm spacing. Composition was taken at the cross points of the mesh. The change between the sampling points was achieved by digital beam control. Multiple fields wcre mcasurcd to accumulate enough points for high accuracy. Analysis indicated that a total of over 100 points was needed for each sample ${ }^{[20]}$.

The analysis was conducted on a JEOL JSM-6400 Scanning Electron Microscope (SEM) equipped with a fully automated PGT EDS. The operating voltage was $20 \mathrm{kV}$ and the current of the condensing lens was $0.3 \mathrm{nA}$. Live sampling time for each point was 30 seconds. Multi-element standards were used for the analysis since the bulk composition of the samples was already known.

Cast structures analyzed were either samples solidified after DTA (Differential Thermal Analysis) tests or cut from industrial ESR (Electroslag Remelting) or VAR (Vacuum Arc Remelting) ingots. DTA tests were done on TA-1600 using samples of about $170 \mathrm{mg}$ and the cooling rate of $20^{\circ} \mathrm{C} / \mathrm{min}$. The alloy $718 \mathrm{VAR}$ ingot had a diameter of $510 \mathrm{~mm}$. The diameter of the alloy 706 ESR ingot was $915 \mathrm{~mm}$. All the samples were polished but not etched.

Measured compositions were sorted to get a profile of composition vs. solid volume fraction in the dendrite structure. Details of the data presentation can be found in $\operatorname{Ref}^{[18,20]}$

\section{Solid fraction measurement}

Solid fraction during solidification was obtained by quenching. A special kit shown in Figure 1 was designed and installed inside a DTA chamber for the test. The specimen was positioned on top of the flat end of the pure alumina rod. The specimen held its shape by the surface tension of the liquid when it was molten. When a designated quenching temperature was reached, the specimen was pushed off the top of the ceramic rod by the pure alumina tube, as shown in Figure 1. The specimen fell and was immediately quenched into the oil bath. Two differentially-connected thermocouples were positioned at the side of the alumina rod at a height just below the specimen. The thermocouples monitored the temperature and the phase transition in the sample. Figure 2 shows a curve recorded by the differential thermocouples, which clearly illustrates the melting points and the quench temperature. Actual tests show that the setup had very high reproducibility. The standard deviation in recorded melting point for an alloy is less than $1.5^{\circ} \mathrm{C}$.

The quenching scheme was: heat to $1100^{\circ} \mathrm{C}$ at $100^{\circ} \mathrm{C} / \mathrm{min}$, change to $20^{\circ} \mathrm{C} / \mathrm{min}$ and heat to a temperature $30^{\circ} \mathrm{C}$ over the alloy melting temperature (load the specimen when the temperature reaches $1150^{\circ} \mathrm{C}$ in the meantime), soak for 3 minutes, cool down at $5^{\circ} \mathrm{C} / \mathrm{min}$. The specimen was pushed off and quenched as soon as the cooling temperature had reached a set point. The specimen weighed about $100 \mathrm{mg}$. Flowing argon was used to protect the specimen.

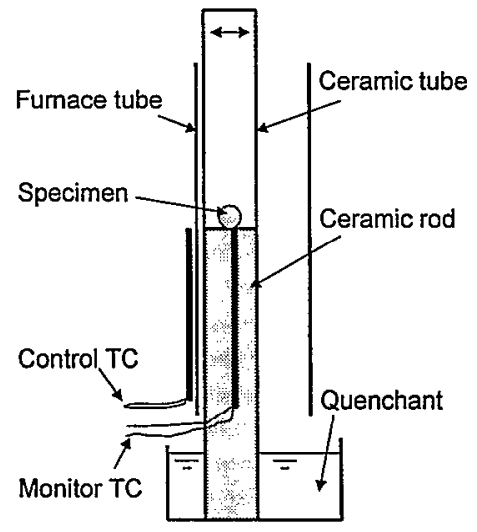

Figure 1 Test kit for the quenching of solidifying liquid

Table I Composition and solidification temperature of the alloys used in the study

\begin{tabular}{|c|c|c|c|c|c|c|c|c|c|c|c|c|c|}
\hline \multirow[b]{2}{*}{ Alloy } & \multirow[b]{2}{*}{ Raw Material } & \multicolumn{9}{|c|}{ Composition, wt $\%$} & \multicolumn{3}{|c|}{ Transition temperature ${ }^{\forall},{ }^{\circ} \mathrm{C}$} \\
\hline & & $\mathrm{Ni}$ & $\mathrm{Cr}$ & $\mathrm{Fe}$ & $\mathrm{Nb}$ & Mo & $\overline{\mathrm{Ti}}$ & $\mathrm{Al}$ & $\mathrm{C}$ & $\mathrm{Si}$ & $\mathrm{T}_{\mathrm{L}}$ & $\mathrm{T}_{\mathrm{S}}$ & $T_{E}$ \\
\hline 718 & VAR & 53.52 & 18.19 & 17.77 & 5.41 & 3.01 & 0.98 & 0.56 & 0.039 & 0.03 & 1337 & $\sim 1260$ & 1164 \\
\hline 706 & ESR & 41.39 & 16.30 & 37.03 & 2.98 & 0.12 & 1.70 & 0.19 & 0.012 & 0.05 & 1388 & 1336 & 1172 \\
\hline 625 & Billet & 60.11 & 22.09 & 4.40 & 3.53 & 9.10 & 0.29 & 0.26 & 0.024 & 0.03 & 1352 & 1290 & 1155 \\
\hline
\end{tabular}

${ }^{7}$ Data from DTA tests with a scan rate of $20^{\circ} \mathrm{C} / \mathrm{min}$. $\mathrm{T}_{\mathrm{L}}$ and $\mathrm{T}_{\mathrm{E}}$ are from the cooling curves. $\mathrm{T}_{S}$ is from the heating curves. 
Two methods were used to determine the solid fraction in the quenched samples. One was the systematic manual point count method $^{[19]}$. The other was image processing. SEM backscattered electron images taken from an as-polished specimen were processed and analyzed by the software ScionImage. Both counting methods produced almost the same results. Therefore no mention is made for the method of analysis in presenting the data.

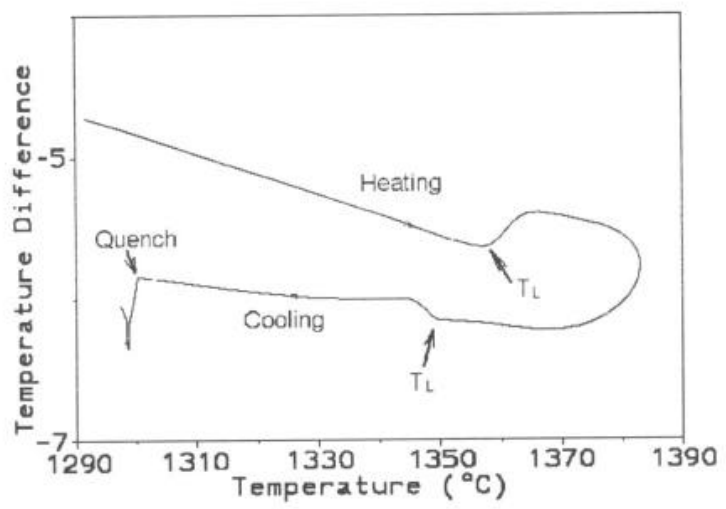

Figure 2 Typical heating and cooling curve recorded for the quenching test

\section{$\underline{\text { Results }}$}

\section{Microsegregation of alloys}

A solidified dendrite microstructure can be clearly identified in the backscattered image of SEM, Figure 3. Because of the segregation of niobium and molybdenum into the interdendritic region, the dendrite cores are dark and the interdendritic areas are brighter. The brightest spots in the interdendritic region are Laves phase and carbide.

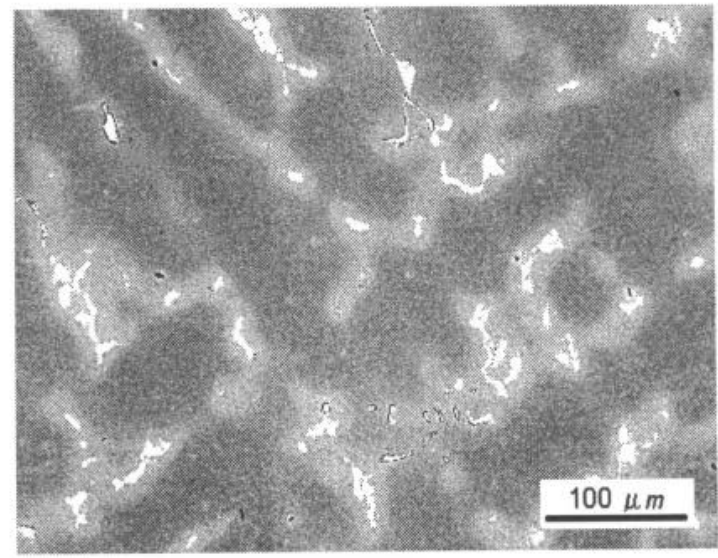

Figure 3 Dendrite structure of alloy 718 solidified at $20^{\circ} \mathrm{C} / \mathrm{min}$ of DTA test

The segregation profile The measured $\mathrm{Nb}$ composition of every point is plotted against its sequence of sampling in Figure 4. This graph represents the random nature of the sampling method. Therefore, there is a wide scattering in the data. The $\mathrm{Nb}$ content in some sampling points is low, corresponding to points located at or close to dendrite cores. Some points have extremely high $\mathrm{Nb}$ content, where the sampling points are located either on Laves phases or carbides.

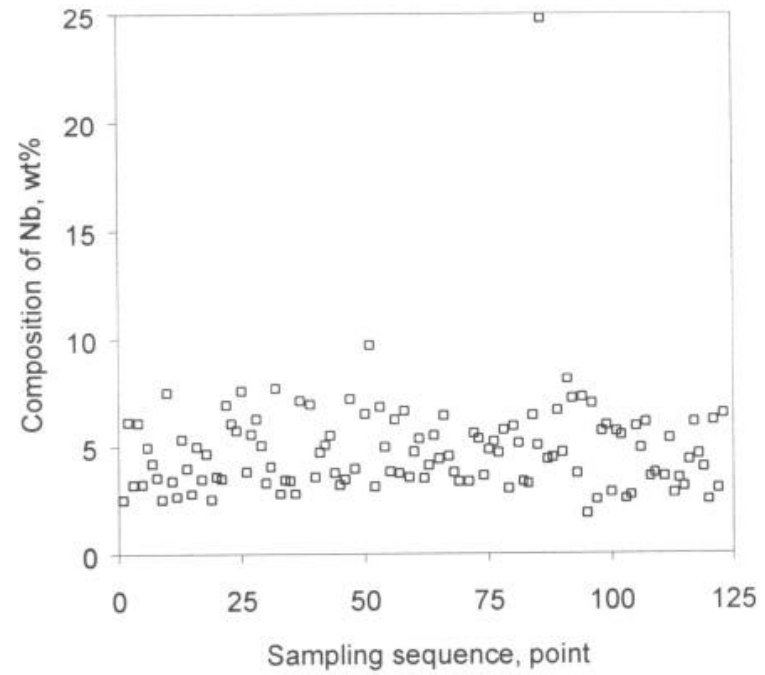

Figure 4 The composition of $\mathrm{Nb}$ vs. the sequence of sampling in VAR 718 alloy

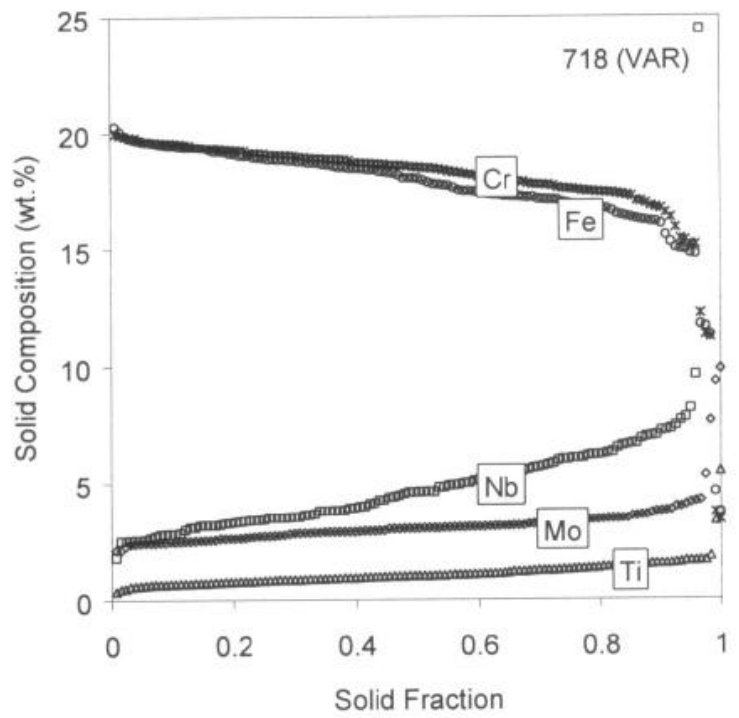

Figure 5 The solid segregation profile in VAR remelted 718 alloy

The apparently random compositions of all the points were sorted to obtain a segregation profile in the solid. Figure 5 is the sorted profile of $\mathrm{Nb}$, and other solute elements for VAR alloy 718. It is proposed that this method is able to provide the complete segregation profiles across the whole solidification range.

The composition of the interdendritic liquid was calculated from the measured segregation profiles in solid. Assuming that the Scheil solidification condition is satisfied, i.e., no back diffusion in solid and complete solute mixing in the liquid, the composition of the interdendritic liquid at a solid fraction $f_{s}$ for any solute element can be computed by the mass conservation principle ${ }^{[20]}$. 


$$
C_{L}=\frac{1}{1-f_{s}}\left(C_{0}-\int_{0}^{f_{s}} C_{S} d f_{s}\right)
$$

Where $C_{0}$ is the alloy composition, $C_{S}$ is the solid composition at a solid fraction $f_{S}, f_{L}$ is the liquid fraction and $f_{S}+f_{L}=1$. Resultant liquid segregation profiles are illustrated in Figure 6. These liquid composition profiles will be used to evaluate the density gradient across the mushy zone.

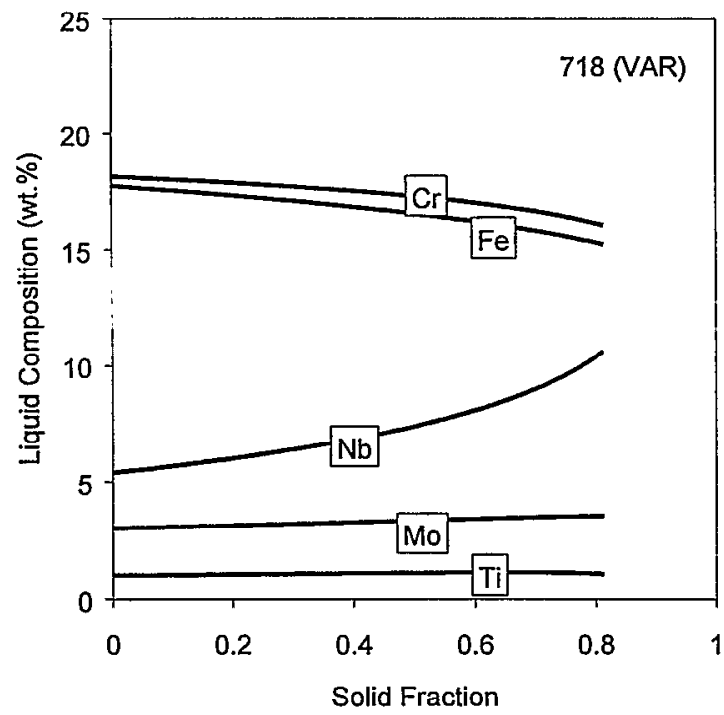

Figure 6 Computed composition profile of the interdendritic liquid during the solidification of alloy 718 in VAR remelting

The segregation characteristics The partition coefficient $k$ for each element at a given solid fraction $f_{S}$, can be calculated as the ratio of the solid composition to the liquid composition, $k=C_{S} / C_{L}$. The results are shown in Figure 7 for alloy 718 . The partition coefficients of $\mathrm{Nb}, \mathrm{Mo}$ and $\mathrm{Ti}$ are smaller than 1 . They are positive segregation elements, i.e., their contents in the liquid becomc highcr as solidification proceeds (Figure 6). Nb has the smallest $k$ among the three elements. It is more severely segregated in alloys. $\mathrm{Cr}$ and $\mathrm{Fe}$ are slightly negatively segregated $(k>1)$ and therefore concentrated in dendrite cores, as shown in Figure 5 . It is consistently observed that the segregation of $\mathrm{Ti}$ in the ESR or VAR structure is smaller than in the DTA solidified structure. This may be because the cooling rates in industrial alloys are much lower, $2^{\circ} \mathrm{C} / \mathrm{min}$ in VAR/ESR ingots compared to $20^{\circ} \mathrm{C} /$ min in DTA test.

The partition coefficients are dependent on the base composition of the alloys. Figure 8 shows $k$ values of $\mathrm{Nb}, \mathrm{Ti}$ and Mo for alloy 625 and 706 . Those of the VAR 718 alloy are also displayed in the figure for comparison purpose. The $k$ of $\mathrm{Nb}$ and $\mathrm{Ti}$ decreases in the sequence from 625,718 to 706 . This follows the trend that alloy 625 has the least iron and alloy 706 has the most iron. This suggests the dependence of the coefficients with the iron contents in the base alloys.

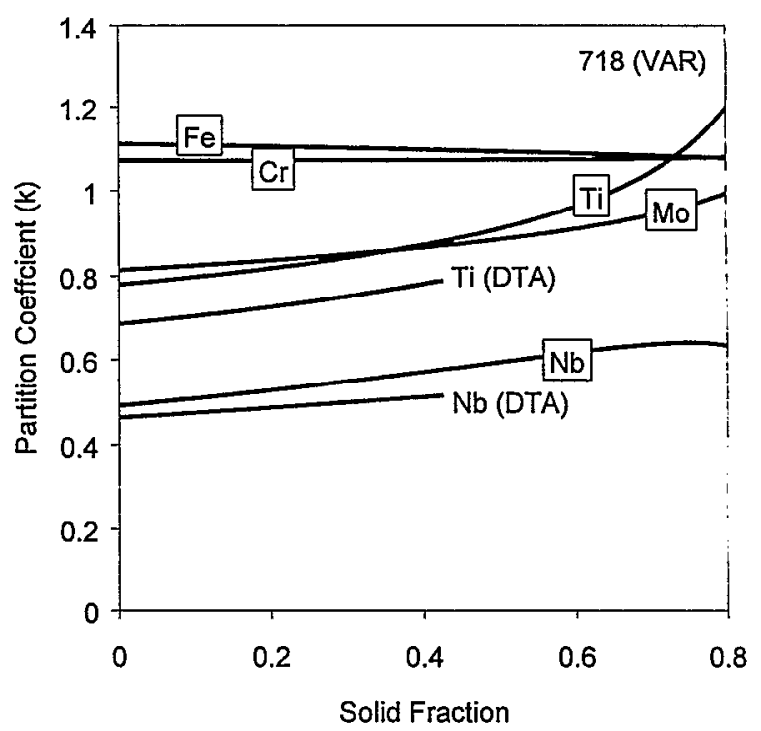

Figure 7 Partition coefficients of solute elements in 718 VAR ingot and DTA sample

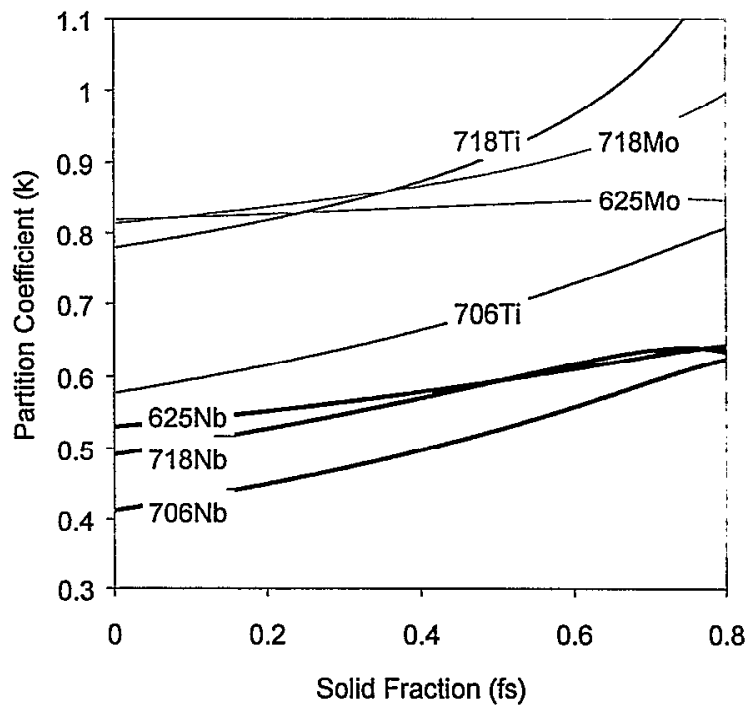

Figure 8 Comparison of elemental partition coefficients in the three alloys. 718 is measured from VAR structure, 706 is from ESR structure, 625 is from DTA sample

Precision of the analysis The above random sampling method also provides an accurate measurement of the segregation profiles. Figure 9 shows the accuracy analysis by a Monte-Carlo simulation using similar parameters as in the SEM/EDS random sampling experiment ${ }^{[20]}$. The standard deviations involved in the measured solid and the calculated liquid composition profiles change with the solid fraction. At smaller solid fraction, the deviation from actual composition is very small. The inaccuracy increases rapidly as the solid fraction approaches unity. This implies that the random sampling method can give accurate segregation results, unless the solid fraction is too high. The recommended limit of the solid fraction is $f s<0.6 \sim 0.8$. 
The random sampling has several advantages over some other methods. First it has very high accuracy. Second, it provides continuous segregation profiles covering most of the solidification range. Most other methods can only measure segregation at specific volume fractions, e.g., initial solid composition or eutectic composition. Therefore, the density gradient in the mushy zone can be accurately accessed by this method. Another merit of the method is that it uses conventionally solidified structure, no special specimen preparation is required.

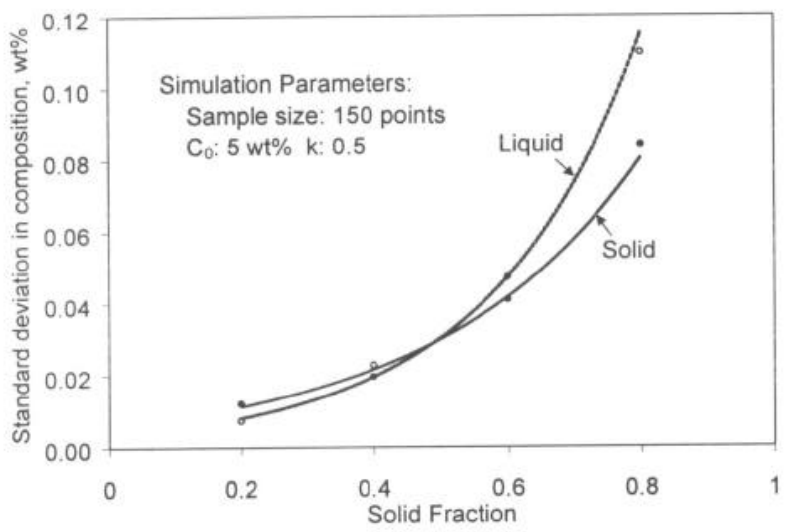

Figure 9 Standard deviation of the measured solid and calculated liquid compositions at different solid fractions in the SEM/EDS random sampling segregation profile analysis.
In addition to the accurate segregation profiles, the development of the segregation with temperature has to be determined to obtain the density gradient in mushy zone. This is because density changes across mushy zone come from both solutal and thermal effects, and that the thermal effect sometimes even forms a significant part of the overall density change in nickel-base alloys $^{[15]}$. The temperature-segregation relation was investigated by the quenching study of solidifying liquid.

\section{Solid development during solidification}

Quenched microstructure of alloy 718 can be found in Figure 10. The rapid quenching chilled the interdendritic liquid and produced the fine microstructure located between the coarse dendrites formed during the slow cooling from the melting temperature. The interdendritic area looks brighter in SEM backscattered image because of the greater segregation of $\mathrm{Nb}$ and $\mathrm{Mo}$.

The composition of the interdendritic areas and the dendrite cores were measured by SEM/EDS. The result can be found in Figure 11 and Table II, respectively. The measured composition of the interdendritic area is consistent with the calculated profiles by the random sampling of conventional cast structure. The dendrite core composition indicates there was some back diffusion of Ti during prolonged holding at high temperature. But the diffusion did not produce statistically significant composition change, especially for other solute elements. It seems that the cooling rate of $5^{\circ} \mathrm{C} / \mathrm{min}$ was fast enough to suppress strong back diffusion in the solid.
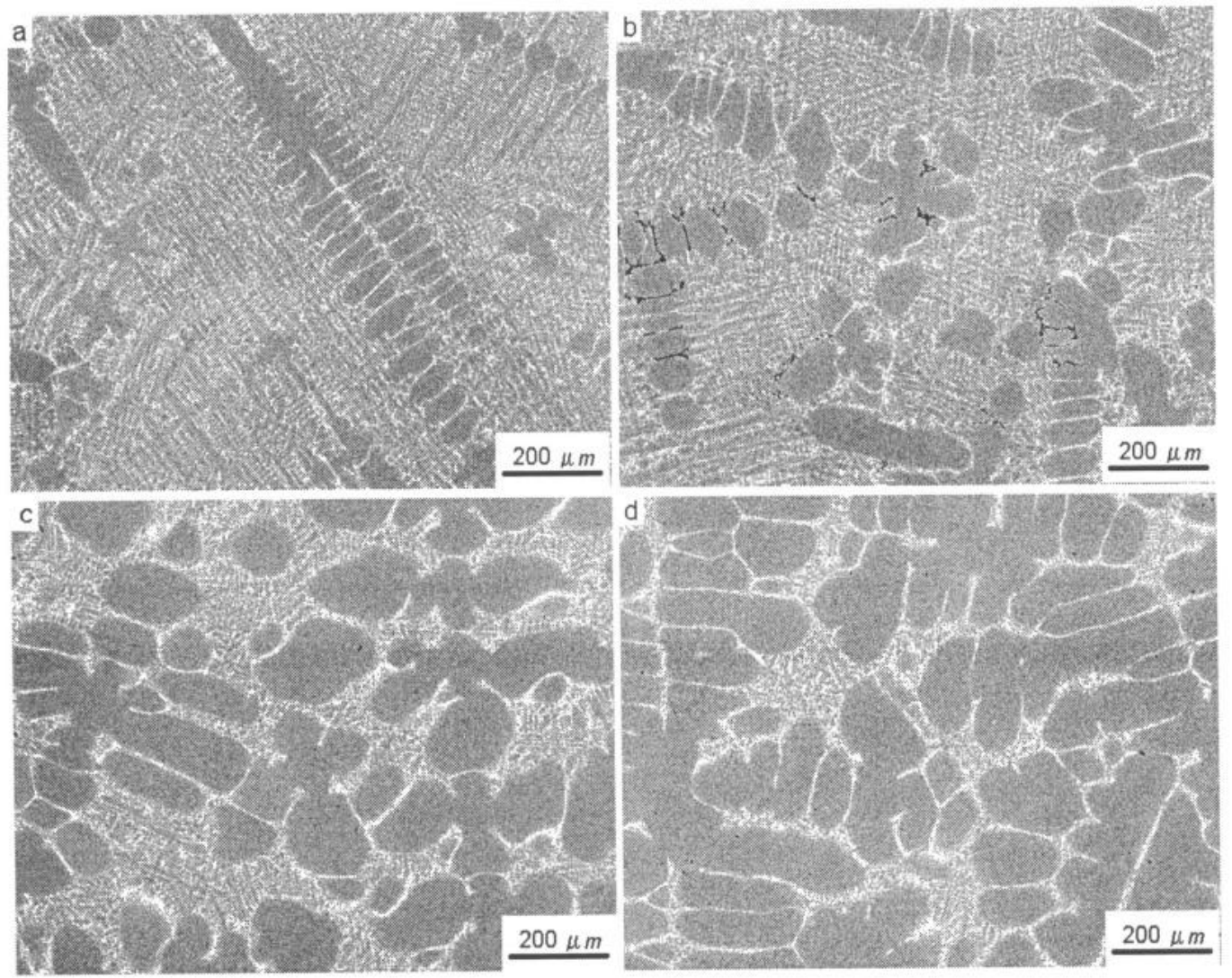

Figure 10 Quenched microstructure of alloy 718

a) $\Delta \mathrm{T}=-2.6^{\circ} \mathrm{C}$; b) $\Delta \mathrm{T}=-7.6^{\circ} \mathrm{C}$; c) $\Delta \mathrm{T}=-27.6^{\circ} \mathrm{C}$; d) $\Delta \mathrm{T}=-47.6^{\circ} \mathrm{C}$; 
Table II Dendrite core composition of alloy 718 quenched at different cooling temperatures

\begin{tabular}{cccccccc}
\hline$\Delta \mathrm{T}$ & $\mathrm{Ni}$ & $\mathrm{Cr}$ & $\mathrm{Fe}$ & $\mathrm{Mo}$ & $\mathrm{Nb}$ & $\mathrm{Ti}$ & $\mathrm{Al}$ \\
\hline-2.6 & 55.35 & 18.76 & 20.04 & 2.85 & 2.03 & 0.47 & 0.50 \\
-7.6 & 55.45 & 19.13 & 19.75 & 2.72 & 1.85 & 0.52 & 0.57 \\
-17.6 & 55.56 & 18.94 & 20.30 & 2.23 & 1.84 & 0.54 & 0.59 \\
-27.6 & 55.14 & 19.11 & 19.94 & 2.70 & 2.05 & 0.52 & 0.54 \\
-47.6 & 55.24 & 19.05 & 19.46 & 2.76 & 2.40 & 0.59 & 0.50 \\
-97.6 & 55.29 & 19.32 & 19.57 & 2.18 & 2.35 & 0.66 & 0.64 \\
\hline
\end{tabular}

$\Delta \mathrm{T}=\mathrm{T}-\mathrm{T}_{\mathrm{L}}, \mathrm{T}_{\mathrm{L}}-$ alloy melting point, $\mathrm{T}-$ quench temperature

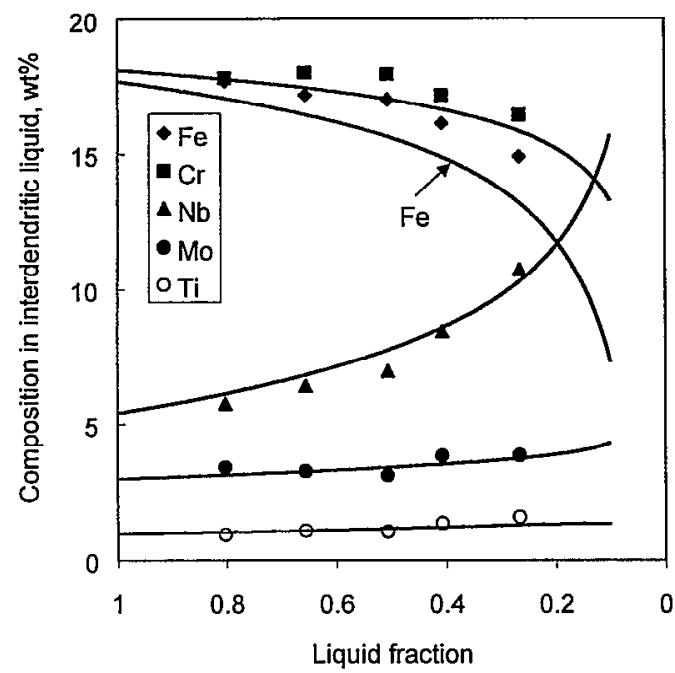

Figure 11 Comparison of the compositions of the interdendritic area in the quenched microstructure (dots) and those calculated from random sampling of DTA sample (lines).

Solid fraction Figure 12 is the plot of the solid fraction vs. the temperature cooled from the alloy melting point, which is expressed as the temperature drop $\Delta \mathrm{T}=\mathrm{T}-\mathrm{T}_{\mathrm{L}}$. Here $\mathrm{T}_{\mathrm{L}}$ is the averaged cooling melting point of each alloy. $T$ is the quench temperature. The transformation of liquid to solid is relatively fast during the solidification. At a temperature drop of $20^{\circ} \mathrm{C}$, more than $50 \%$ of the liquid has already solidified for both alloys. At the same temperature drop from the alloy liquidus, the solid content in alloy 625 is consistently higher than in alloy 718 .

Prediction of the solid fraction Though experimental measurement of the solid fraction during solidification by quenching or other means is effective, it is very tedious. Theoretical calculation methods were explored to predict the quantity from alloy composition or from the segregation profile measured. These include Thermo-Calc and empirical alloy melting point equation.

In the Thermo-Calc analysis, Thermo-Calc $M$ version and the allelement nickel-iron database were used ${ }^{[21]}$. Both equilibrium solidification and Scheil solidification modes were assumed in the calculation.

The melting temperature equation used is

$$
T_{L}=T_{0}+\sum_{i} m_{i} C_{i}
$$

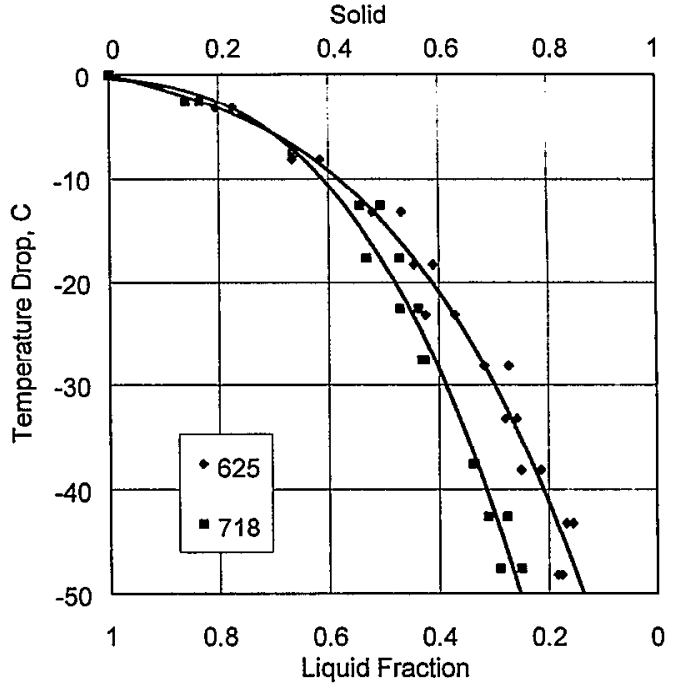

Figure 12 The transformation of liquid to solid during solidification

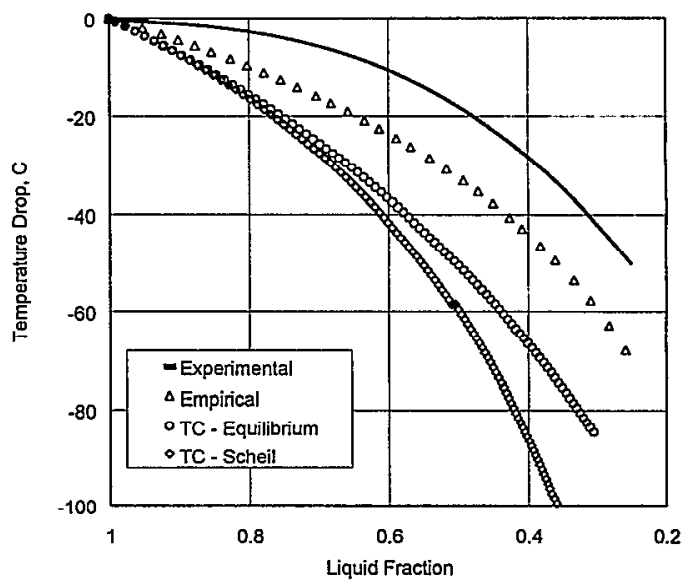

Figure 13 The solid formation in the mushy zone of alloy 718 predicted by Thermo-Calc and the empirical melting point equation.

where $T_{L}$ is the melting point of an alloy, in ${ }^{\circ} \mathrm{C} . \mathrm{C}$ is the composition of an element in nickel base alloy, in wt\%. $\mathrm{T}_{0}$ and $\mathrm{m}$ are constants (Table III). This equation is a linear regression of the melting points of a series of alloys based on $\mathrm{Ni}-20 \mathrm{Cr}^{[22]}$. The composition range covers $\mathrm{Nb} 0 \sim 14$, Ti $0 \sim 5.5$, Mo 0 9, Al 0 1.5, Co $0 \sim 18$, Fc $0-36$, C 0-0.36, Si 0 1.95. Eq.(2) offers a way to correlate the solid fraction, interdendritic liquid composition and temperature. 
Table III Constants for the melting point calculation of $\mathrm{Ni}-20 \mathrm{Cr}$ based alloys

\begin{tabular}{ccccccccccc}
\hline Element & $\mathrm{Co}$ & $\mathrm{Cr}$ & $\mathrm{Fe}$ & $\mathrm{Nb}$ & $\mathrm{Mo}$ & $\mathrm{Ti}$ & $\mathrm{Al}$ & $\mathrm{C}$ & $\mathrm{Si}$ & $\mathrm{T}$ \\
\hline $\mathrm{M}$ & 0.86 & 0.75 & -0.16 & -12.3 & -5.24 & -18 & -14.63 & -27.56 & -29.45 & 1455 \\
\hline
\end{tabular}

Figure 13 shows the calculated and the experimentally measured liquid fractions. The difference is large for Thermo-Calc results. Neither equilibrium nor Scheil solidification of Thermo-Calc gives results close to experiment. The deviation also enlarges as temperature drops, when the interdendritic liquid becomes more and more enriched with $\mathrm{Nb}$ and other solute elements. Therefore, the difference in Thermo-Calc calculation can not be narrowed by compensating the undercooling effect, back diffusion in the solid or other kinetic factors.

The interdendritic liquid composition in the random sampling method was input in the empirical melting point equation (2) to get the melting temperature. Obtained temperature - liquid fraction results are sketched in Figure 13. They are closer to experimental ones. The difference becomes stabilized after the initial transition at the low solid fractions. A temperature difference of about $12^{\circ} \mathrm{C}$ is observed between the calculated and experimental results. This temperature difference is of the same order as that of the undercooling. Therefore it is expected that the empirical melting point equation can be used to predict the solid evolution speed in the mushy zone if the undercooling correction is made.

\section{The freckle tendency}

\section{$\underline{\text { Relative Rayleigh number }}$}

Many criteria were proposed in the literature for freckle prediction and prevention. Through careful examination of these criteria using experimental results, Flemings' macrosegregation criterion was found best for defining freckle phenomenon ${ }^{[23]}$. The explanation of the criterion is that if the flow of interdendritic liquid along crystal growth direction is faster than the crystal growth speed, freckle defect will be developed as a result of the structural instability ${ }^{[2]}$. Figure 14 is a schematic showing the crystal growth and the interdendritic flow at the tilted solidification front of remelting, where $\mathbf{V}$ is the velocity of the interdendritic flow, $\mathbf{R}$ is the crystal growth speed. According to Flemings' theory, freckle is expected to form in the tilted solidifying mushy zone if the derivative of $\mathrm{V}$ in the $\mathrm{R}$ direction is greater than $\mathrm{R}$.

The velocity of the interdendritic flow, $\mathbf{V}$, can be obtained by Darcy's law, which describes the liquid flow through porous media. However, for the remelting process, two factors make the computation more complex. One is the tilt angle of the solidification front, $\beta$. The other is the the angle $\alpha$, which is needed to maintain a negative density gradient to drive the flow along the solidification front. Therefore the interdendritic flow velocity will have the following form if both angles are considered:

$$
\mathrm{V}=\frac{\Delta \rho g \Pi}{v f_{L}} f(\alpha, \beta)
$$

Where $\Delta \rho$ is the density difference, $\Delta \rho=\left(\rho-\rho_{0}\right) / \rho_{0}, \rho_{0}-$ density at alloy melting temperature, $\mathrm{g}$ - gravity, $v$ - viscosity of interdendritic liquid, $\Pi$ - permeability of mushy zone, $f_{L}-$ local liquid fraction. The tilt effect of the solidification front and the deviation of the flow from the front are included in the function $f(\alpha, \beta)$.

The comparison of the derivative of $\mathrm{V}$ in $\mathrm{R}$ direction results in the following criterion:

$$
R a=\frac{\Delta \rho g \Pi}{v f_{L}} \cdot \frac{1}{R} \cdot F(\alpha, \beta)
$$

This is a criterion written in the form of a Rayleigh number. But its physical meaning is that same as Flemings'. In Eq.(4), $F(\alpha, \beta)$ considers both the $\mathrm{f}(\alpha, \beta)$ in Eq.(3) and taking the derivative of $\mathrm{V}$ in the $\mathrm{R}$ direction.

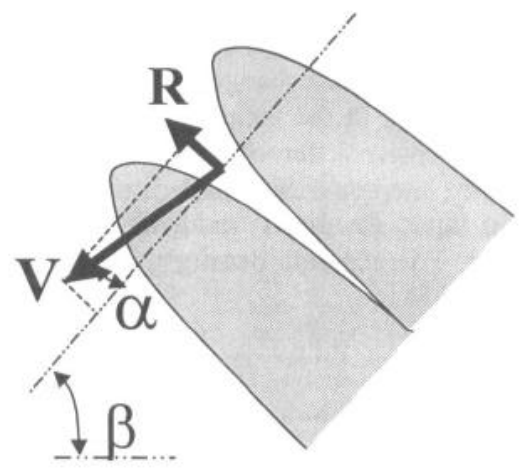

Figure 14 The interdendritic liquid flow pattern at the tilted solidification front of remelting. $\beta$ is the slope angle of the solidification front, $\alpha$ is the deviation of interdendritic flow from the slope plane, $\mathrm{V}$ is the velocity of the interdendritic liquid flow, $\mathrm{R}$ is the crystal growth velocity.

Exact calculation of equation (4) requires, first of all, the definition of the slope effect, the function $F(\alpha, \beta)$, which is not understood at the present time. Accurate information of the dendrite spacing and physical parameters of interdendritic liquid is also required to calculate the permeability and other parameters. A reasonable approach to use the equation for freckle study is through some simplification.

For semi-quantitative analysis considering the composition effects, dendrite parameters, pool slope and physical parameters can be neglected, provided that the alloys studied have similar constituents and are processed under similar remelting schemes. If the permeability factor in equation (4) is split into two multiplying terms, $\Pi=\Pi\left(f_{L}\right) \cdot \Pi(G, R)$, with the first part considering the influence of solid fraction and the second part the processing (dendrite) effect, equation (4) can be simplified to:

$$
R a_{r}=\frac{\Delta \rho \cdot \Pi\left(f_{L}\right)}{f_{L}}
$$


This criterion considers only the composition effect, it can be used to compare the freckle tendency of similar alloys. Therefore we will call it relative Rayleigh number in the sections followed. In equation (5), $\Pi\left(f_{L}\right)$ is the overall permeability in mushy zone. For the flow along secondary dendrite arms, $\Pi\left(f_{L}\right)$ usually takes the form $\Pi\left(f_{L}\right) \propto f_{L}^{3.34}$ for a given liquid fraction ${ }^{[25]}$. Detailed discussion about its calculation can be found in $\operatorname{Ref}^{[23]}$.

\section{Freckle tendency of the alloys}

With the segregation profile and the solid formation information, it is possible to quantitatively evaluate the freckle tendency of an alloy. Density of the interdendritic liquid was calculated by the molar addition method ${ }^{[26,27]}$ using the software Metals. In the calculation, correction was made to include the mixing effect proposed by Sung et $a{ }^{[28]}$. Compared to the experimental measurements of the liquid density of several superalloys ${ }^{[28]}$, the error in our calculation was less than $4 \%$.

Obtained density changes of the three alloys studied are illustrated in Figure 15. The density difference is calculated relative to the alloy's density at its liquidus temperature. $\Lambda$ s the liquid fraction decreases, there are both changes in the composition of interdendritic liquid and in the temperature. Therefore, Figure 15 shows the overall density difference from both solutal effect and thermal effect. The interdendritic liquid density in alloys 718 and 625 increases as liquid fraction is reduced. Alloy 706 shows the opposite behavior. The absolute density gradient increases in the order 706,625 and 718 .

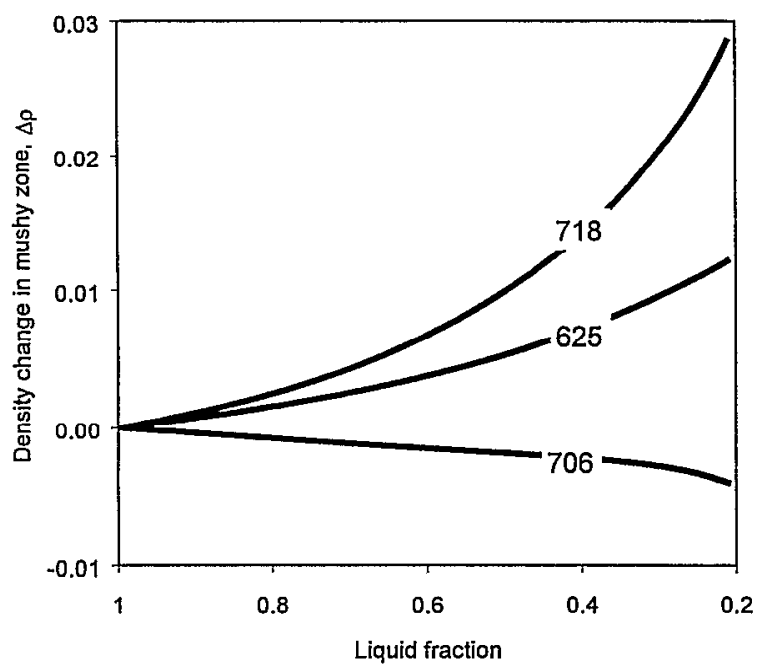

Figure 15 Density difference of interdendritic liquid in mushy zone of industrial alloys

Figure 16 shows the calculated relative Rayleigh number for the alloys. It is revealed that the maximum Rayleigh number value is not reached at the bottom of the mushy zone, where $f_{L} \rightarrow 0$. Instead, it is reached mid-way in the mushy zone. The reason is that there are two competing factors controlling overall Rayleigh number. One is the density, which increases monotonically as liquid fraction decreases, giving greater driving force for liquid flow.
However, the decrease in liquid fraction eventually overweighs this density difference effect, giving greater resistance to the flow. Therefore, a peak effect is observed. For 706 the maximum is reached at about $40 \%$ solid fraction. In 718 this is at about $60 \%$ solid fraction. Freckle flow most likely initiates in a place where the maximum $\mathrm{Ra}$ value is reached. Therefore, freckle flow starts deeper in the mushy zone in 718 alloy.

Comparing the maximum value of $\mathrm{Ra}_{\mathrm{r}}$ for the three alloys, 718 has the highest Rayleigh number and alloy 706 has the lowest. This corresponds to industrial observations that alloy 706 is the easiest to remelt in the three alloys. Much larger ingots can be made from the alloys. Alloy 718 is the most difficult to process. Usually the ingot diameter is limited to about $510 \mathrm{~mm}$ for high $\mathrm{Nb}$ rotor grade chemistry.

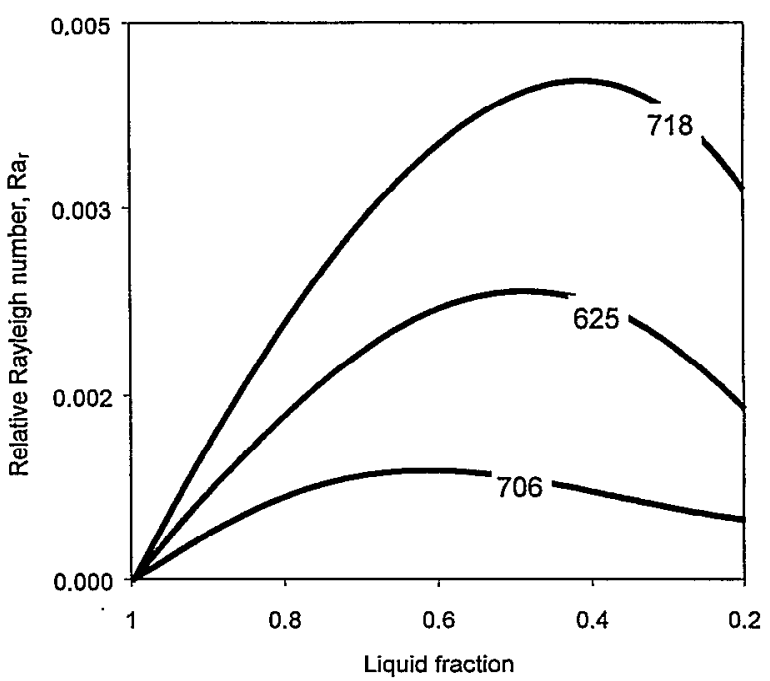

Figure 16 Estimated relative Rayleigh number for the industrial alloys

\section{Alloying effect on freckle tendency}

The above evaluation of the freckle tendency reveals why alloy 718 is prone to freckles. The alloy happens to have a combination of both high density gradient and a slow solid growth development as a result of the high content of $\mathrm{Nb}$ and its strong segregation nature. Generally, the trend in the Rayleigh numbers of the three alloys follows that of the density gradient, i.e., higher density gradient implies higher possibility of freckling. Therefore, the primary choice of alloying is to reduce the density gradient resulting from the elemental segregation. Among the major alloy strengtheners, $\mathrm{Nb}$ strongly segregates into the interdendritic liquid and makes the liquid there heavier. $\mathrm{Ti}$, on the other hand, segregates into the same place. Therefore, one approach to reduce the segregation related density gradient is to balance the alloying of both elements. 706 is a good example of this balanced alloying. The alloy has a reduced content of Niobium and a higher $\mathrm{Ti} / \mathrm{Nb}$ ratio. Even though the alloy contains a large amount of $\mathrm{Fe}$, which makes the $\mathrm{Nb}$ segregate more severely, the tendency to freckle is reduced. 


\section{Conclusions}

For the evaluation of the freckle tendency of an alloy, quantitative determination of the segregation behavior and the solid growth during the solidification are pertinent for the calculation of the density distribution and permeability inside the mushy zone. The study explored methods to obtain the necessary data by experimental measurement and theoretical calculation. Based on the precise measurement of the segregation hehavior in cast structures and the solid formation process, the freckle tendency was examined for three commercial alloys. The trend in the calculated relative Rayleigh number follows the melting observations that alloy 718 is the most freckle prone and alloy 706 the least.

1. The segregation profiles in $\mathrm{Nb}$-containing superalloys were obtained by SEM/EDS analysis using the random sampling method. This method has the capability to provide high precision continuous composition profiles from as-cast materials from industrial ingots or laboratory solidified samples.

2. The progressive development of solid was studied using quenching method. It was found that the speed of the solid evolution during solidification is very fast for the alloys studied. At the same degree of cooling, more solid is formed in alloy 625 than in alloy 718 .

3. More accurate prediction of the solid formation during solidification can be accomplished by the empirical melting point equation. Further development in the thermodynamic analysis and the database is needed to improve its accuracy of calculation.

4. Density gradient and relative Rayleigh number calculation reveals that alloys 718 and 625 have a positive density gradient in the mushy zone, alloy 706 has a slightly negative density gradient. The freckle tendency predicted by the relative Rayleigh number decreases in the sequence 718,625 and 706. Among the three alloys, alloy 718 has the highest freckle potential.

\section{Acknowledgment}

This research was carried out under the project "Composition effects on macroscopic solidification segregation of superalloys", sponsored by Special Metals Corporation. Dr. Shailesh Patel, Director of $R \& D$, is thanked for his continuous support of the project. The authors would like to acknowledge Mrs. Diane Schwegler-Berry and Mr. Joel Harrison, National Institute of Occupational Safety and Health, Morgantown, WV, for their help with SEM/EDS analysis. They are also grateful to Dr. Peter Quested, National Physics Laboratory, UK, for providing the software "Metals" for the calculation of liquid metal density. The public domain software Scionlamge was used for the quantitative image analysis. The authors would like to extend their appreciation to the software developers at the National Institute of Health (www.nih.gov). Prof. Pollock and the program committee of the $9^{\text {th }}$ International Symposium on Superalloys are sincerely thanked for their reading and comments on the paper, which helped to avoid many technical and spelling mistakes.

\section{$\underline{\text { References }}$}

1. K. O. Yu, J. A. Domingue, G. E. Maurer, et al. "Macrosegregation in ESR and VAR processes," JOM, (1993), 49-51.

2. A. D. Helms, C. B. Adasczik, L. A. Jackman, "Extending the size limits of cast/wrought superalloy ingots," Superalloys 1996, eds. R. D. Kissinger, et al., TMS, 1996, 427-433.

3. S. V. Thamboo, "Melt related defects in alloy 706 and their effects on mechanical properties," Superalloys 718, 625, 706 and Various Derivatives, ed. E. A. Loria, TMS, 1994, 137-152.

4. A. F. Giamei and B. H. Kear, "On the nature of freckles in nickel base superalloys," Metall. Trans., 1(1970), 2185-2192.

5. J. J. Moore, and N. A. Shah, "Mechanisms of the formation of A- and V- segregation in cast iron," Int. Met. Rev., 28 (12) (1983), 338-356.

6. J. A. Brooks, J. S. Krafcik, J. A. Schneider et al., "Fe segregation in $\mathrm{Ti}-10 \mathrm{~V}-2 \mathrm{Fe}-3 \mathrm{Al} 30$ inch VAR ingot $\beta$-fleck formation," Proc. 1999 Inter. Symp. On Liquid Metal Processing and Casting, eds. A. Mitchell et al, Vacuum Metallurgy Div., American Vacuum Soc., Santa Fe, New Mexico, Feb 21-24, 1999. 130-144.

7. S. M. Copley, A. F. Giamei, S. M. Johnson et al., "The origin of freckles in unidirectional solidification of nickel base crystals," Metall. Trans., 1(1970), 2193-2204.

8. J. R. Sarazin and A. Hellawell, "Channel formation in $\mathrm{Pb}-\mathrm{Sn}$, $\mathrm{Pb}-\mathrm{Sb}$, and $\mathrm{Pb}-\mathrm{Sn}-\mathrm{Sb}$ alloy ingots and comparison with the system $\mathrm{NH}_{4} \mathrm{Cl}-\mathrm{H}_{2} 0$," Metall. Trans. A, 19A(1988), 1861-1871.

9. C. F. Chen, "Experimental study of convection in a mushy layer during directional solidification," J. Fluid Mech., 293(1995), 81-98.

10. R. J. McDonald and J. D. Hunt, "Convective fluid motion within the interdendritic liquid of a casting," Metall. Trans., 1(1970), 1787-1788.

11. S. N. Tewari, R. Shah, "Macrosegregation during dendritic arrayed growth of hypoeutectic $\mathrm{Pb}-\mathrm{Sn}$ alloys: influence of primary arm spacing and mushy zone length," Metall. Trans A, 27A(1996), 1353-1362.

12. S. D. Felicelli, D. R. Poirier and J. C. Heinrich, "Modeling freckle formation in three dimensions during solidification of multicomponent alloys," Metall. Mater. Trans. B, 29B(1998), 847855.

13. P. Auburtin, S. L. Cockcroft, A. Mitchell et al., "Center segregation, freckles and development directions for niobium containing superalloys," Superalloys 718, 625, 706 and Various Derivatives, ed. E.A. Loria, TMS 1997, 47-54.

14. J. Van Den Avyle, J. Brooks, and A. Powell, "Reducing defects in remelting processes for high-performance alloys," JOM, 50 (3) (1998), 22-25. 
15. W. Chen, W. H. Yang, K.-M.Chang et al. Proc. 1999 Inter. Symp. On Liquid Metal Processing and Casting, eds. A. Mitchell et al, Vacuum Metallurgy Div., American Vacuum Soc., Santa Fe, New Mexico, Feb 21-24, 1999, 122-129.

16. P. Auburtin, S. L. Cockcroft, and A. Mitchell, "Freckle formation in large superalloy single crystal airfoil castings," Proceedings: Materials for Advanced Power Engineering, v5, Part III, eds. J. Lecomte-Becker et al., 1998, 1459-1468.

17. N. Mori and K. Ogi, "Study on formation of channel-type segregation," Metall. Trans. A, 22A(1991), 1663-1672.

18. M. N. Gungor, "A statistically significant experimental technique for investigating microsegregation in cast alloys," Metall. Trans. A, 20A(1989), 2529-2533

19. Annual Book of ASTM Standards, "Standard Test Method for Determining Volume Fraction by Systematic Manual Point Count," vol. 03.01, Designation E 562-89, 1995, pp. 583-588.

20. W. H. Yang, W. Chen, K.-M. Chang, S. Mannan, J. deBarbadillo "Monte Carlo sampling for the microsegregation measurement in cast structures", accepted for publication in Mater. Metall. Trans. A.

\section{Bo Sundman, User's Manual of Thermo-Calc, Ver.L, 1997.}

22. Yang, L., Phase control in Nb-hardened superalloys, MS Thesis, West Virginia University, 1997.

23. W. H. Yang, W. Chen, K.-M. Chang, S. Mannan, J. deBarbadillo Freckle Criteria for the Directional Solidification of Alloys, submitted to Mater. Metall. Trans. A. for publication

24. R. Mehrabian, M. Keane, and M. C. Flemings, "Interdendritic fluid flow and macrosegregation: influence of gravity," Metall. Trans., 1(1970), 1209-1220.

25. D. R. Poirier, "Permeability for flow of interdendritic liquid in columnar-dendritic alloys," Metall. Trans. B, 18B(1987), 245255.

26. A. F. Crawley, "Densities of liquid metals and alloys," Int. Metall. Rev., 19(1974), 32-48.

27. K.C. Mills, P. N. Quested, "Measurements of the physical properties of liquid metals," Liquid Metal Processing and Casting Conf. Proc., AVS, eds. A. Mitchell et al., Sept. 1994, 226-240.

28. P. K. Sung, D.R.Poirier, E. McBride, "Estimating densities of liquid transition-metals and Ni-base superalloys," Mater. Sci. and Engg., A231(1997), 189-197. 